\title{
PANDANGAN MUFASSIR TENTANG KONSEP BELAJAR MENGAJAR
}

\author{
Adnan Syarif \\ Institut Agama Islam Syarifuddin Lumajang, Indonesia \\ E-mail: adnansyarifiais@gmail.com \\ Haidar Idris \\ Institut Agama Islam Syarifuddin Lumajang, Indonesia \\ E-mail: haidaridris8@gmail.com
}

\begin{abstract}
Abstrak: Tulisan ini ingin menunjukkan konsepsi para Ahli Tafsir dan bahkan Mufassir tentang belajar dalam Islam. Karena menggunakan sudut pandang mufassir, penelitian ini akan melihat pandangan para mufassir tentang konsep belajar secara spesifik di Alqur'an. Bagaimana cara mereka menafsiri dan seterusnya. Konsepsi belajar dalam al-Qur'ān berbeda dengan konsepsi belajar yang biasa ditemukan dalam dunia pendidikan selama ini. Hal ini bisa dilihat pada ayat pertama yang diturunkan Allah SWT kepada Nabi Muhammad saw ketika bertahanus di Gua Hira'. Ayat yang pertama kali turun memerintahkan kepada beliau untuk membaca dengan menyebut nama Tuhannya yang menciptakan, Jibril berkata "iqra' bismi rabbika" (bacalah dengan nama Tuhanmu). Kesimpulan dari penelitian ini menunjukkan bahwa Al-Maraghi, Ibnu Kathir, 'Ali al-Shabuni dan Muhammad Qurais Shihab memiliki perbedaan pendapat dalam memaknai ayat-ayat tentang konsep belajar. Perbedaan lebih terlihat dalam penentuan perintah belajar dan mengajar. Mana yang didahulukan dan apakah perintah untuk nabi secara pribadi atau untuk umatnya, termasuk konsepsi tentang belajar dan mengajar, adakah belajar lebih dulu dari pada mengajar.
\end{abstract}

Kata Kunci: Mufassir, Belajar Mengajar

\section{Pendahuluan}

Konsepsi belajar dalam al-Qur'ān berbeda dengan konsepsi belajar yang biasa ditemukan dalam dunia pendidikan selama ini. Hal ini bisa dilihat pada ayat pertama yang diturunkan Allah SWT kepada Nabi Muhammad saw ketika bertahanus di Gua Hira'. Ayat yang pertama kali turun memerintahkan kepada beliau untuk membaca dengan menyebut nama Tuhannya yang menciptakan, Jibril berkata "iqra' bismi rabbika" (bacalah dengan nama Tuhanmu).

Rasulullah SAW bersabda: "Mencari ilmu (belajar) wajib hukumnya bagi setiap orang Islam". Dan pada kesempatan lain beliau pun pernah menganjurkan, agar manusia mencari ilmu meski berada di negeri orang (Cina) sekalipun; meski dari manapun datangnya. Hadith tentang belajar dan mengajar banyak disebut dalam al- 
Hadith, demikian juga dalam al-Qur'an al-Karim. Hal ini merupakan indikasi, bahwa betapa belajar dan mengajar sangat penting artinya bagi umat manusia. Dengan belajar manusia dapat mengerti akan dirinya, lingkungannya dan juga Tuhan-nya. Dengan belajar pula manusia mempu menciptakan kreasi unik dan spektakuler yang berupa teknologi.

Syari'at Islam memberikan perhatian sangat besar terhadap ilmu pengetahuan. Banyak ayat dan Hadits yang memerintahkan kaum Muslimin untuk mencari ilmu. Rasulullah SAW dalam beberapa Hadithnya juga memerintahkan mencari ilmu bagi setiap Muslim.

$$
\text { وعن أنس رضي الله عنه قال : قال رسول الله صلى الله عليه وسلم : من خرج في طلب العلم فهو }
$$

\section{Analisis Isi Surat Al-'Alaq}

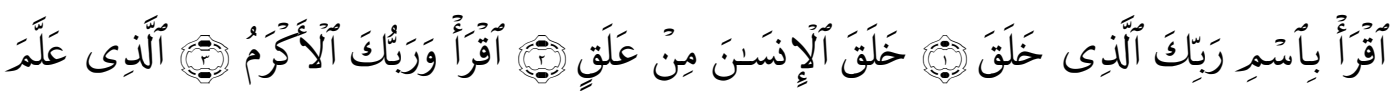

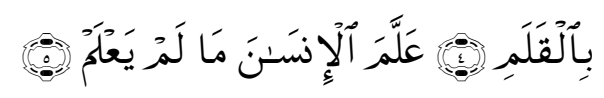

عن أنس رضي الله عنه قال: قال رسول الله صلى الله عليه وسلم: طلب العلم فريضة على كل مسلم (رواه الطبراني) وفي رواية: طلب العلم فريضة على كل مسلم وإن طالب العلم يستغفر له كل شيئ حتى الحيتان في البحر (حديث صحيح لابن عبد البر في العلم)

Surat ini oleh para ulama' disepakati turun di Mekah sebelum Nabi Muhammad saw hijrah. Para ulama juga sepakat, bahwa wahyu al-Qur'an yang pertama turun adalah lima ayat pertama surat al-'Alaq. Atas dasar inilah, Thabathaba’i berpendapat, dari konteks uraian ayat-ayatnya, maka tidak mustahil bahwa keseluruhan ayat-ayat surat ini turun sekaligus. ${ }^{2}$

\footnotetext{
${ }^{1}$ Muhyiddin Abi Zakariya Yahya ibn Syarif al-Nuri, Riyadh al-Shalibin (Surabaya: al- Hidayah, T.th), 530.

${ }^{2}$ Muhammad Husain al-Thabathaba'i, Al-Mizan Fi Tafsir Al-Qur'an, Juz 10 (Beirut: Lebanon: T.th.), 369. 
Berbeda dengan pendapat di atas, Ibnu 'Asyur sebagaimana dikutip oleh Quraish Shihab berpendapat bahwa lima ayat surat al-'Alaq turun pada tanggal 17 Ramadlan. ${ }^{2}$ Pendapat kedua inilah yang banyak diikuti oleh kebanyakan ulama. Nama yang populer pada masa sahabat Nabi saw adalah surat Iqra’ Bismi Rabbika. Namanya yang tercantum dalam sekian banyak mushaf adalah surat al-'Alaq, namun juga ada yang menamainya dengan surat iqra'.3

Menurut Ibnu Katsir bahwa surat al-'Alaq ayat 1-5 merupakan surat yang berbicara tentang permulaan rahmat Allah yang diberikan kepada hamba-Nya, awal dari nikmat yang diberikan kepada hamba-Nya dan sebagai tanbih (baca: peringatan) tentang proses awal penciptaan manusia dari 'alaqah. Ayat ini juga menjelaskan kemuliaan Allah SWT. yang telah mengajarkan manusia sesuatu hal (pengetahuan) yang belum diketahui, sehingga hamba dimuliakan Allah dengan ilmu yang merupakan qudrat-Nya. ${ }^{4}$

Menurut Wahbah al-Zuhaili, terdapat pula munasabah antara surat al-Tin ayat-4 dengan surat al-'Alaq sebagai penjelasan dengan bentuk manusia yang merujuk pada surat al-'Alaq ayat 2, yaitu bahwa manusia diciptakan dari segumpal darah serta dalam bentuk yang paling sempurna (paling baik dibandingkan dengan bentuk makhluk lainnya). ${ }^{5}$

\section{Konsep Belajar Mengajar Dalam al-'Alaq Menurut Para Tokoh}

\section{Al-Maraghi}

Al-Maraghi menafsirkan ayat 1 surat al-'Alaq dengan mengatakan: ${ }^{6}$

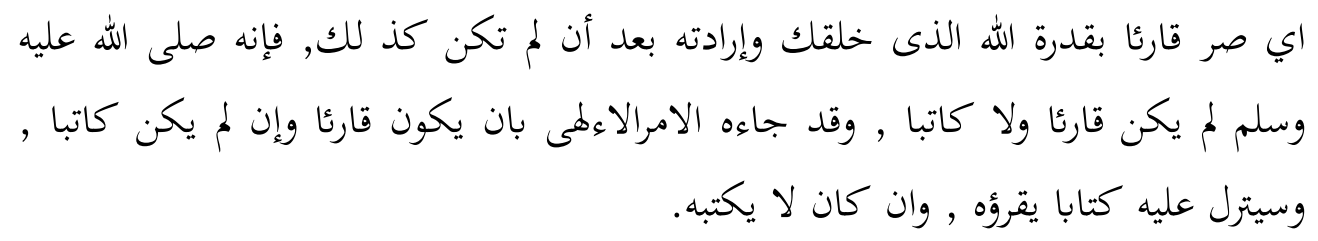

3 M. Quraish Shihab, Tafsir al-Misbah: Pesan, Kesan dan Keserasian al-Qur'an, Vol. 15 (Jakarta: Lentera Hati, 2004), 391.

4 Abu al-Fida al-Hafiz ibn Katsir al-Dimisqi, Tafsir al-Qur'an al-'Adzim, Jilid 4 (Beirut: Dar-al-Fikr, T.th.), 645.

5 Wahbah al-Zuhaili, Tafsir al-Munir fi al-'Aqidah wa al-Syari'ah wa al-Manbaj (Lebanon: Dar al-Fikr alMu'ashir, t.th.), 311.

${ }^{6}$ Ahmad Musthafa al-Maraghi, Tafsir al-Maraghi (Beirut : T.p, 1974), 198. 
"Jadilah engkau orang yang bisa membaca berkat kekuasaan dan kehendak. Allah yang telah menciptakanmu. Sebelum itu, beliau tidak pandai membaca dan menulis. Kemudian datang perintah Ilahi agar beliau membaca, sekalipun tidak bisa menulis. Oleh karena itu, Allah menurunkan sebuah kitab kepadanya untuk dibaca sekalipun beliau tidak bisa menulisnya."

Realisasi perintah اقر أ pada ayat tersebut tidak mengharuskan adanya suatu teks tertulis sebagai objek bacaan, dan tidak pula harus diucapkan, sehingga terdengar oleh orang lain. Karena dalam beberapa kamus ditemukan beraneka ragam arti dari kata tersebut, antara lain: menyampaikan, menelaah, membaca, mendalami, meneliti, mengetahui ciri-ciri sesuatu dan lain sebagainya yang semua bermuara pada arti menghimpun. ${ }^{7}$

\section{Abu al-Fida al-Hafiz Ibnu Kathir al-Dimashqi}

Menurut Ibnu Katsir, bahwa surat al-'Alaq ayat 1-5 merupakan salah satu permulaan rahmat Allah dari sekian ni'mat Allah kepada hambanya. Hal ini dapat dilihat dari ungkapannya sebagai berikut: ${ }^{8}$

$$
\text { وهن اول رحمة رحم الله بها العباد وأول نعمة أنعم الله بها عليهم , وفيها التبيه على ابتداء خلق }
$$

"Itu adalah awal dari salah satu rahmat-rahmat Allah yang diberikan kepada hambanya, dan awal dari salah satu ni'mat-ni'mat Allah yang diberikan kepada hambanya. Di dalam ayat itu mengandung peringatan tentang awal penciptaan manusia dari segumpal darah. Sesungguhnya salah satu dari kemuliaan Allah adalab mengajarkan manusia dari sesuatu yang ditidak tahu, kemudian memuliakan manusia dengan ilmu."

Di dalam pendapat yang telah disampaikan oleh Ibnu Katsir di atas, dinyatakan bahwa dalam surat al-'Alaq ayat 1-5 mengandung peringatan tentang awal dan dari apa manusia diciptakan. Selain itu juga tentang bagaimana Allah memuliakan hambanya yang bernama manusia daripada hambanya yang lain. Di sini ditegaskan bahwa Allah memberikan ilmu kepada manusia agar ia menjadi makhluk yang mulia. Akan tetapi seseorang tidak mungkin dapat memperoleh

7 M. Quraish Shihab, Membumikan al-Qur'an,Fungsi dan Peran Wabyu Dalam Kehidupan Masyarakat (Bandung: Mizan, 1998), 167.

8 Abu al-Fida al-Hafiz ibn Katsir, Tafsir al-Qur'an, 645.

252 |Tarbiyatuna: Jurnal Pendidikan Islam; Volume 11, Nomor 2, Agustus 2018 p-ISSN: 2085-6539; e-ISSN: 2242-4579 
ilmu itu tanpa melalui proses belajar. Maka dari itu, untuk memperoleh kemuliaan atau derajat yang lebih tinggi daripada makhluk Allah yang lainnya, manusia diharuskan untuk belajar, menggali dan memperdalam ilmu pengetahuannya.

\section{Muhammad 'Ali al-Shabuni}

Beliau berpendapat mengenai ayat di atas sebagai berikut: ${ }^{9}$

$$
\begin{aligned}
& \text { هذا أول خطاب إلهي وجه إلى النبي ص.م وفيه دعوة إلى القراءة والكتابة والعلم , لأنه شعار } \\
& \text { دين الإسلام أي إقرأ يا يُجَّم القران مبتدئا ومستعينا باسم ربك الجليل , الذي خلق جميع } \\
& \text { المخلوقات , وأوجد جميع العوالم. }
\end{aligned}
$$

"Ayat ini merupakan awal seruan ilabi kepada nabi saw. Di dalamnya terkandung nilai dakwah (ajakan) untuk membaca, menulis dan hikmah. Karena hal itu merupakan usaha syiar agama Islam. Maksudnya bacalah hai Mubammad al-Qur'an dengan diawali dan dengan pertolongan nama Tubanmu yang Maha Lubur, yaitu dzat yang menciptakan segala makhluk, mewujudkan segala ilmu."

Perintah membaca dari Allah dalam konteks mencari kearifan (wisdom) juga mempunyai implikasi membaca fenomena alam dan fenomena sosial dengan segala dinamika yang tidak pernah berhenti. Hal ini juga terlihat dalam surat al-Ghaasyiyah ayat 17-20 yang berbunyi:

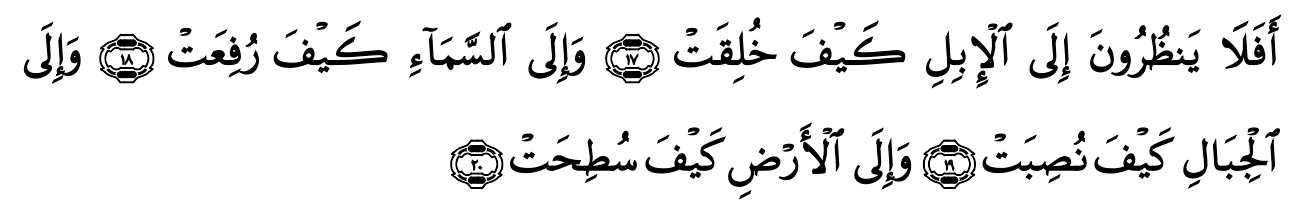

Artinya: Maka apakah mereka tidak memperhatikan unta bagaimana dia diciptakan, dan langit, bagaimana ia ditinggikan, dan gunung-gunung bagaimana ia ditegak.kan, dan bumi bagaimana ia dihamparkan. (QS. Al-Ghaasyiyah : 17-20). ${ }^{10}$

Alam dan lingkungan seharusnya merupakan kelas terbuka untuk aktivitas pembelajaran. Dampak positif dari cara pandang ini adalah alam dipandang sebagai the mother nature (baca: ibu pertiwi). Sebagai ibu yang dihormati setiap anak, haram besar untuk dikotori dengan tindakan-tindakan yang tidak bertanggung jawab. Lingkungan sekitar bisa memperlihatkan kenyataan, bahwa manusia sering memperlakukan bumi sebagai "prostitute"

\footnotetext{
${ }^{9}$ Muhammad 'Ali al-Sabuni, Safwat al-Tafasir (Beirut: Dar al-Fikr, T.th), 581.
}

10 Al-Quran dan Terjemahnya (Semarang: al-Syifa, 1992), 1054. 
dalam rangka pemuasan diri tanpa batas. ${ }^{11}$ Dengan demikian, membaca bukan sekedar fenomena melihat tulisan sebagai catatan, namun juga terkandung maksud agar manusia bisa belajar untuk peka terhadap situasi dan kondisi sekitar. Dengan demikian, surat al-'Alaq ayat 1-5 memiliki korelasi dengan pembelajaran. Sebab surat al-'Alaq ayat 1-5 merupakan alat pendidikan yang secara langsung memperkenalkan tradisi baca dan tulis yang merupakan sarana yang digunakan manusia untuk belajar.

\section{M. Quraish Shihab}

Beliau berpendapat bahwa, kata iqra' ( اقر أ ) berasal dari kata kerja qaraa ( قرأ ) yang pada mulanya berarti menghimpun, sehingga apabila huruf atau katanya dirangkai dan mengucapkan rangkaian kata itu, maka berarti telah menghimpunnya atau membacanya. Dengan demikian, realisasi perintah tersebut tidak mengharuskan adanya suatu teks tertulis sebagai objek bacaan, dan tidak pula harus diucapkan, sehingga terdengar oleh orang lain. ${ }^{12}$ Dan kemudian ayat itu dilanjutkan dengan kata ربك باسم adapun menurut Imam 'Alauddin bahwa:

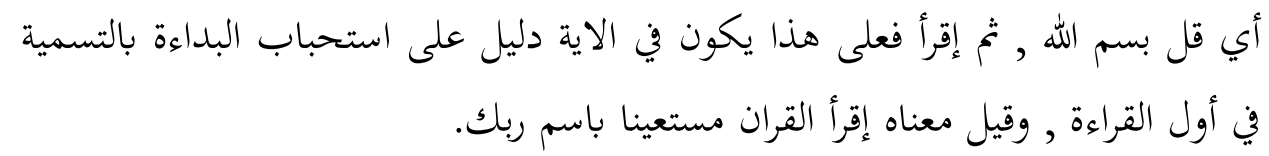

"Katakanlah bismillah kemudian bacalah, maka atas perintah dalam ayat ini merupakan dalil disunahkannya membaca basmalah pada permulaan bacaan dan dikatakan bacalah al-Qur'an dan meminta pertolongan dengan menyebut nama Tuhanmu."

Oleh karena itu, dalam suatu riwayat dinyatakan Menurut M. Quraish Shihab bahwa objek membaca pada ayat-ayat yang menggunakan akar kata qara'a ditemukan bahwa ia terkadang menyangkut suatu bacaan yang bersumber dari Tuhan (al-Qur'an dan kitab suci sebelumnya), misalnya dalam surat al-Isra' ayat 45 dan Yunus ayat 94, dan terkadang juga objeknya adalah

11 Abdurrahman Mas'ud, Antologi Studi Agama dan Pendidikan (Semarang: Aneka Ilmu, 2004), 73.

12 M. Quraish Shihab, Membumikan al-Qur'an, 393.

13 Imam 'Alauddin 'Ali ibn Muhammad ibn Ibrahim al-Baghdadi, Tafsir al-Khaz̧in, juz. VI, (Beirut: Darul Kutub al-Ilmiah, T.th), 447. 
suatu kitab yang merupakan himpunan karya manusia atau dengan kata lain bukan bersumber dari Allah, misalnya dalam surat al-Isra' ayat $14 .^{14}$

Dari uraian di atas dapat dikatakan bahwa perintah membaca disini tidak sekedar membaca tek tertulis saja, akan tetapi lebih menekankan pada konsep tazkiyat al-nafs (penyucian jiwa) pada diri sang pembaca atau pada diri seseorang yang sedang melakukan aktifitas belajar.

Dari hasil analisis pandangan tokoh-tokoh di atas, dapat dipahami bahwa dalam surat yang pertama kali diturunkan kepada nabi Muhammad, manusialah yang mendapat mandat sebagai peserta didik yang diberi pelajaran langsung oleh Allah dan pendidik untuk menyampaikan apa yang telah mereka terima, pernyataan di atas telah dinyatakan dalam penyebutan manusia dalam surat al-Alaq ayat ke-dua dan penyebutan manusia yang ke-dua kali dalam ayat yang ke-lima,ayat tiga diatas mengulangi perintah membaca. Walaupun ulama berbeda pendapat tentang tujuan pengulangan itu, ada yang menyatakan bahwa perintah pertama ditujukan kepada priadi nabi muhammad saw, sedangkan perintah pertama ditunjukkan kepada ummatnya, atau yang pertama untuk membaca dalam shalat, sedangkan yang kedua di luar shalat. Pendapat ketiga menyatakan yang pertama perintah belajar, sedang yang kedua adalah perintah mengajar orang lain. ada lagi yang menyatakan bahwa perintah kedua berfungsi mengukuhkan guna menemukan rasa percaya diri kepada Nabi Muhammaad Saw. Tentang kemampuan beliau membaca-karena tadinya beliau tidak pernah membaca.

Dalam hadits juga banyak dijumpai bagaimana konsep belajar dalam Islam. Seperti hadits: ${ }^{15}$

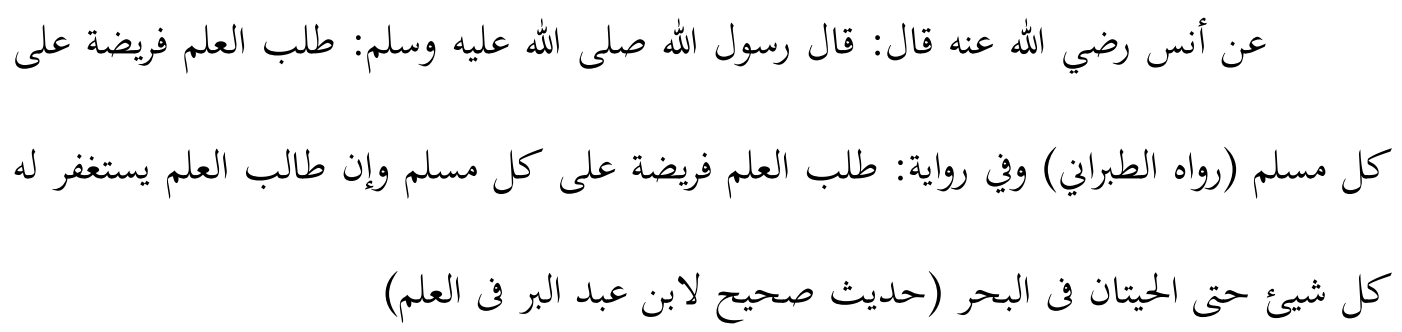

${ }^{14}$ M. Quraish Shihab, Membumikan al-Qur'an, 167.

${ }^{15}$ Al-Jami' ash-Shaghir, 132, Hadits No. 5267 
Dalam hadith ini dikatakan bahwa mengkaji ilmu merupakan pekerjaan mulian dan karenanya maka orang yang keluar dari rumahnya mencari ilmu dengan ikhlas, maka seluruhnya akan mendoakan termasuk ikan di laut.

Hadits tersebut didukung hadits lain yang diriwayatkan oleh Tirmidhi:

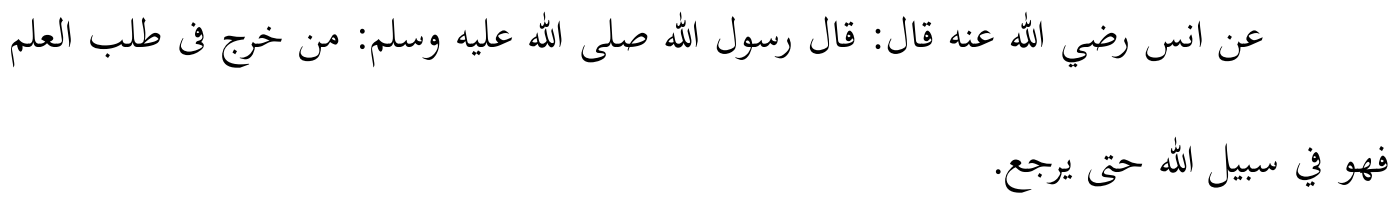

Dari Anas r.a berkata: Rasulullah SAW bersabda: Barang siapa keluar rumah untuk mencari ilmu maka dia berada di jalan Allah sampai meninggal dunia (HR. Tirmidhi).

\section{Kesimpulan}

Belajar adalah merupakan proses suatu kegiatan dan bukan suatu hasil atau tujuan. Belajar bukan hanya mengingat, akan tetapi lebih luas itu, yakni mengalami. Mengajar lebih identik kepada proses mengarahkan seseorang agar lebih baik. Maka Kewajiban orang yang memiliki ilmu adalah mengamalkannya dalam kehidupan sehari-hari dan mengajarkannya kepada orang lain. Ulama ahli tafsir juga berbedabeda dalam memberikan konsepsi belajar dan mengajar. Tapi prinsipnya, tetap menunjukkan konsepsi belajar dan mengajar dari sudut pandang Islam melalui AlQur'an dan Hadits. Perbedaan pandangan dalam pendapat ulama tafsir, adalah sesuatu yang lumrah karena memiliki sebab sendiri.

\section{Referensi}

al-Baghdadi, Imam 'Alauddin 'Ali ibn Muhammad ibn Ibrahim. T.th. Tafsir al-Khaẓin. Beirut: Dar al-Kutub al-'Ilmiyah, juz. VI

al-Dimishqi, Abu al-Fida al-Hafizibn Kathir. T.th. Tafsir al-Qur'an al-'Azim, Jilid 4. Beirut: Dar al-Fikr.

al-Maraghi, Ahmad Mustafa. 1974. Tafsir al-Maraghi, Beirut

al-Quran dan Terjemahnya, Semarang: al-Shifa, 1992

al-Shabuni, Muhammad 'Ali. T.th. Safwat al-Tafasir. Beirut: Dar al-Fikr

al-Tabataba'i, Muhammad Husain. T.th. Al-Mizan Fi Tafsir al-Qur'an, Juz 10, Beirut: Lebanon. 
al-Zuhaili, Wahbah. T.th. Tafsir al-Munir fi al-'Aqidab wa al-Syari'ah wa al-Manhaj, Lebanon: Dar al-Fikr al-Mu'ashir

an-Nuri, Muhyiddin Abi Zakariya Yahya ibn Syarif. T.th. Riyadlus Shalihin, Surabaya: al- Hidayah,

Mas'ud, Abdurrahman. 2004. Antologi Studi Agama dan Pendidikan. Semarang: Aneka Ilmu

Shihab, M. Quraish. 1998. Membumikan al-Qur'an,Fungsi dan Peran Wabyu Dalam Kebidupan Masyarakat, Bandung: Mizan

2004. Tafsir al-Misbah: Pesan, Kesan dan Keserasian al-Qur'an, Vol. 15. Jakarta: Lentera Hati 